\title{
A Rapid Colorimetric Method for the Determination of Iron in Biological Samples using o-Phenanthroline Method
}

\author{
P. Chandrakiran, A. Shanta Kumari *, M. Sathwik, P. Raghava \\ Department of Pharmaceutical Analysis, Nirmala College of Pharmacy, Mangalagiri, Guntur, Andhra Pradesh, India
}

\begin{abstract}
Address for
Correspondance

A. Shanta Kumari,

Skatakam9@g

mail.com
\end{abstract}

Received:

20.03.2018

Accepted:

15.05.2018

\begin{abstract}
A simple, sensitive and highly selective direct colorimetric method for the determination of Iron in biological samples is developed. Iron reacts with o-phenanthroline and reduced from $\mathrm{Fe} 3+$ to $\mathrm{Fe} 2+$ by the use of an excess of hydroxylamine $\mathrm{HCl}$ to form a orange red complex ion. It was measured at an absorption maximum of $510 \mathrm{~nm}$. Beer's law was obeyed in the concentration range of $20-200 \mu \mathrm{g} / \mathrm{mL}$. The method was applied successfully to a number of biological samples (female wistar rats' liver), plant samples (pearl millet seeds). The method is very simple and requires no solvent extraction or pre-concentration steps. (c) 2018 iGlobal Research and Publishing Foundation. All rights reserved.
\end{abstract}

Cite this article as: Chandrakiran, P.; Kumari, A.S.; Sathwik, M.; Raghava, P. A rapid colorimetric method for the determination of iron in biological samples using o-phenanthroline method. Indo Global J. Pharm. Sci., 2018; 8(2): 76-79.

Keywords Spectrophotometry; Colorimetric; O-Phenanthroline; Biological Samples .

\section{INTRODUCTION}

Iron is essential to all known organisms. In cells, iron is generally stored in the center of metalloprotiens, because free iron can catalyze production of toxic free radicals [1]. Iron deficiency lead to iron deficiency anemia. At present few analytical techniques with sufficient sensitivity and selectivity are available for the determination and speciation of trace and ultra-trace levels of Iron in plant samples. Some of the techniques are Flame atomic absorption method, Solid phase spectroscopy, Non dispersive atomic fluorescence spectrometer, X- ray fluorescence spectroscopy and Electron probe microanalysis. We have developed a novel method for the estimation of iron in both plant (pearl millet seeds) and animal samples (liver).

\section{Prevalence and severity of anemia in India [2-6]}

According to world health organization (WHO), there are two billion people with anemia in the world and half of the anemia is due to iron deficiency. Anemia is late indicator of iron, $48 \%$ in children 5-14 years, $42 \%$ in woman, $15-59 \%$,

$30 \%$ in men $15-59$ years, and $45 \%$ in adults. Anemia and iron deficiency lead to substantial physical productivity deficiency, so it is estimated that the prevalence of iron deficiency is 2.5 times of that of anemia. The estimated prevalence of anemia in developing countries is $39 \%$ in children losses in adults. Iron deficiency during pregnancy is associated with maternal mortality, preterm labor, low birth weight, and infant mortality. In children, iron deficiency affects cognitive and motor development and increases susceptibility to infections.

Anemia is a major problem in India. In the 2005 -2006 National Family Health Survey, a household survey aimed at having national and state representative data on population health and nutrition; the prevalence of anemia was $70 \%$ in children aged 6 to 59 months, 55\% in females aged 15-49 years, and $24 \%$ in males aged $15-49$ years. 


\section{Indo Global Journal of Pharmaceutical Sciences, 2018; 8(2): 76-79}

\section{Principle}

Iron +II reacts with o-phenanthroline to form a colored complex ion. The intensity of the colored species is measured using a spectrophotometer [7]. Determination of iron by reacting iron + II with o-phenanthroline to form an orange-red complex ion according to the following equation:

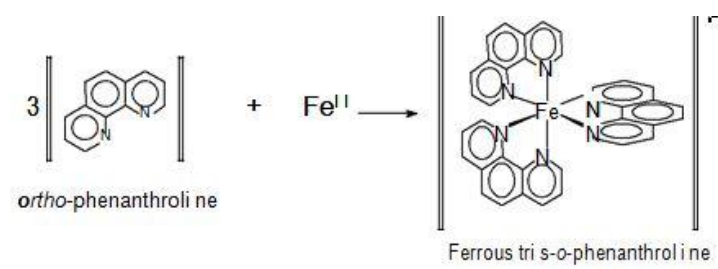

The iron in the biological samples will be present in $\mathrm{Fe}^{3+}$ form. It is reduced from $\mathrm{Fe}^{3+}$ to $\mathrm{Fe}^{2+}$ by the use of an excess of hydroxylamine $\mathrm{HCl}$ in the quantitative estimation.

\section{MATERIALS AND METHODS}

\section{Reagents and solutions}

Analytical grade Ferrous sulphate, Hydroxylamine $\mathrm{HCl}$ and O-Phenanthroline were purchased from Loba Chemie, Mumbai. Triple Distilled water was prepared with all glass distillation unit.

\section{Analytical Procedure [7-9]}

Iron calibration solutions were prepared by pipetting the indicated amounts of the iron solution into labeled $50 \mathrm{~mL}$ volumetric flasks. The first flask is a blank containing no iron and made up to the volume with distilled water. $4.0 \mathrm{~mL}$ of $10 \%$ hydroxylamine $\mathrm{HCl}$ solution and $4.0 \mathrm{~mL}$ of $0.3 \%$ ophenanthroline solution was added to each volumetric flask. The mixture was swirled and allowed the mixture to stand for 10 minutes. Each flask was made to the mark with distilled water and mixed well by inverting and shaking the capped volumetric flasks several times. Using a UV/VIS Spectrophotometer (Spectronic 301, Thermo Scientific Ltd., Mumbai), carefully measured the percent transmittance of the various solutions in the $50 \mathrm{~mL}$ volumetric flask. The concentrations of $\mathrm{Fe}^{3+}$ volume to pipet for 0.05, 0.10, 0.15, 0.20 and $0.25 \mathrm{mg}$ were $4,8,12,16$ and $20 \mathrm{~mL}$ respectively. The absorbance was measured at $510 \mathrm{~nm}$ against a corresponding reagent blank. The iron content in an unknown sample was determined using a concurrently prepared calibration graph.

\section{Determination of Iron in plant samples [10]:}

The air dried sample, 10-25 g of plant tissue (pearl millet seeds) was taken into a glass jar for sprouting of seeds for 7 days for the increase of vitamin $\mathrm{C}$, and the seeds are dried for one day and made into a fine powder. The digest was filtered and neutralized with distilled water and $0.8 \mathrm{~mL}$ of Hydroxyl amine $\mathrm{HCl}$ and $\mathrm{O}$-phenanthroline was added to the filtered solution and made up to $10 \mathrm{~mL}$ with distilled water. The absorbance was measured at $510 \mathrm{~nm}$ against a corresponding reagent blank. The iron content in an unknown sample (pearl millet seeds) was determined using a concurrently prepared calibration graph.

\section{Determination of Iron in biological samples [10]}

In vivo studies on the effect of pearl millet on therapeutic effect of iron supplements in anemic rats were carried out as follows. Sub-chronic toxicity study [10] was conducted on Wistar albino rats of female sex weighing between 120 and $150 \mathrm{~g}$ were obtained from the animal house. The animals were allowed to free access of water and standard palette diet (Hindustan Lever Ltd. Mumbai). Animals were housed in polycarbonate cages, paddy husk bed- ding with a controlled ambient temperature $\left(22 \pm 2{ }^{\circ} \mathrm{C}\right)$, humidity $(60 \pm 5 \%)$ and a 12 $\mathrm{h}$ light/dark cycle. All the experimental procedures and protocols used in the study were reviewed and approved by the Institutional Animal Ethical Committee.

Wistar female rats were randomly divided into 5 groups of 6 rats each. Group A animals were the vehicle control, treated with free access of water and standard palette diet. Group B animals were treated with standard iron syrup $(1 \mathrm{~mL})$, Group $\mathrm{C}$ animals were treated with pearl millet seeds $(1 \mathrm{~g})$ and Group $\mathrm{D}$ animals were administered with combination of pearl millet powder $(0.5 \mathrm{~g})$ and probiotics $(0.5 \mathrm{~g})$, Group $\mathrm{E}$ animals were treated with pearl millet powder $(1 \mathrm{~g})$ and probiotics $(1 \mathrm{~g})$ for 28 days through oral route of administration. After the experimental period the animals were sacrificed $2 \mathrm{~h}$ after last dose administration by cervical dislocation, the thoracic region was opened to expose the heart. Blood was collected by cardiac puncture in dry heparinised tubes and used for estimation of hematological parameters. Another aliquot of blood was placed in plain centrifuge tubes allowed to coagulate for $30 \mathrm{~min}$ in room temperature and centrifuged at $3000 \mathrm{rpm}$ for $10 \mathrm{~min}$. The supernatant serum was collected and used for estimation of biochemical parameters. Immediately following blood collection, the liver was removed, washed in cold saline, pressed between filter paper pads and carefully weighed using a digital weighing balance. Relative organ weights for $100 \mathrm{~g}$ body weight was calculated and recorded. The liver was immediately preserved in $10 \%$ formalin for estimation of iron by colorimetric method.

Estimation of iron in animal organs was estimated as follows [7-9]. The liver was isolated, washed in cold saline, pressed between filter paper pads and carefully weighed using a digital 
Indo Global Journal of Pharmaceutical Sciences, 2018; 8(2): 76-79

weighing balance. Relative organ weights for $100 \mathrm{~g}$ body weight was calculated and recorded. The liver was immediately preserved in $10 \%$ formalin for estimation of iron by colorimetric method. The liver was homogenized and then the supernatant liquid was collected. Then $0.5 \mathrm{~mL}$ of the supernatant liquid was taken into the centrifuge tubes and to that $0.5 \mathrm{~mL}$ of water was added, centrifuged at $3000 \mathrm{rpm}$ for $10 \mathrm{~min}$. After $10 \mathrm{~min}$ collect the supernatant liquid $(0.1 \mathrm{~mL})$ and to that $0.8 \mathrm{~mL}$ of hydroxyl amine $\mathrm{HCl}$ and $0.8 \mathrm{~mL}$ of ophenanthroline was added and stand for few min for proper mixing and made up to $10 \mathrm{~mL}$ with distilled water. Absorbance was measured at a wavelength of $510 \mathrm{~nm}$. Validation of data was performed statistically on all samples.

\section{RESULTS AND DISCUSSION}

The calibration curve for the determination of iron in pearl millet seeds was obtained as shown in Fig 1. The Beer's law followed and in the concentration range of $20-200 \mu \mathrm{g} / \mathrm{mL}$. The regression equation showed a correlation coefficient of 0.999 . The concentration of unknown sample (pearl millet) was found to be $182 \mu \mathrm{g} / \mathrm{mL}$. The calibration curve for the determination of iron in biological samples was obtained as shown in Fig 2. The Beer's law followed and in the concentration range of $20-200 \mu \mathrm{g} / \mathrm{mL}$. The regression equation showed a correlation coefficient of 0.998 . The concentration of unknown sample (liver) was found to be $306 \mu \mathrm{g} / \mathrm{mL}$.

A Study of accuracy was conducted for biological samples in Triplicate $(50 \%, 100 \%, 150 \%)$. The average $\%$ recovery was calculated [15] and shown in Table 1.

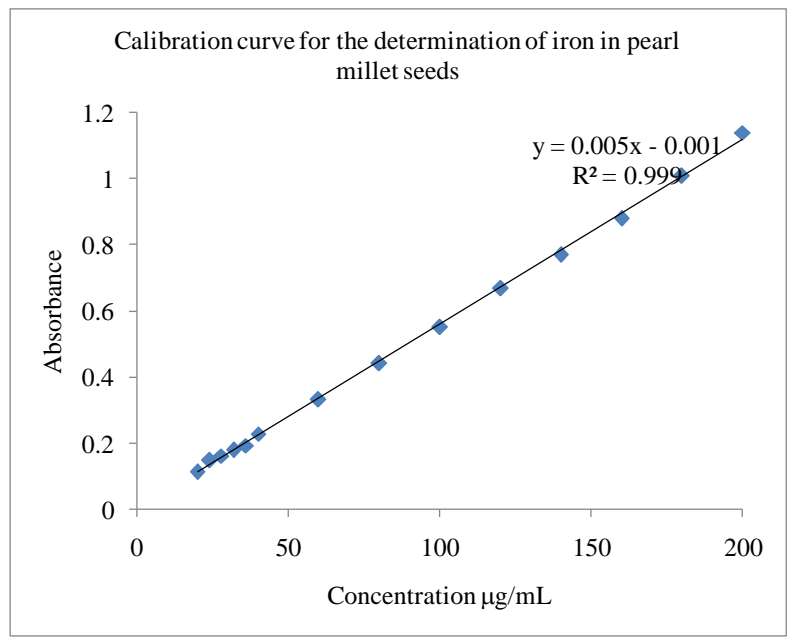

Fig. 1: Calibration curve for the determination of iron in pearl millet seeds

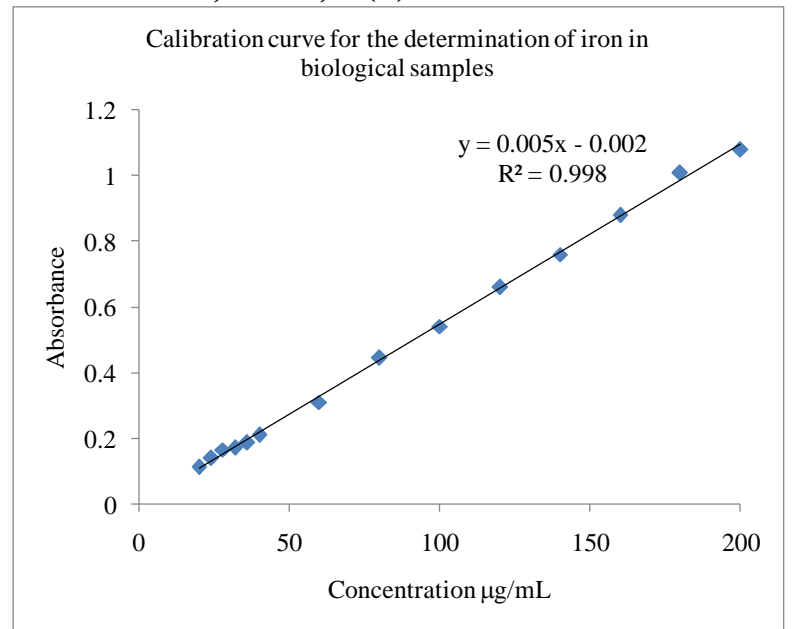

Fig. 2: Calibration curve for the determination of iron in biological sample

Table 1: Accuracy data of iron samples in biological samples

\begin{tabular}{|c|c|c|c|c|c|}
\hline $\begin{array}{l}\text { S.N } \\
\text { 0 }\end{array}$ & $\begin{array}{l}\text { Accura } \\
\text { cy }\end{array}$ & $\begin{array}{l}\text { Amou } \\
\text { nt } \\
\text { added } \\
(\mathrm{mg})\end{array}$ & $\begin{array}{l}\text { Amoun } \\
\text { t } \\
\text { recover } \\
\text { ed }\end{array}$ & $\begin{array}{l}\text { \% } \\
\text { Recovery }\end{array}$ & Results \\
\hline 1. & $50 \%$ & 2.42 & 2.42 & 98.77 & $\begin{array}{l}\text { Mean }=2.4 \\
2\end{array}$ \\
\hline 2. & $50 \%$ & 2.41 & 2.40 & 98.3 & $\mathrm{SD}=0.015$ \\
\hline 3. & $50 \%$ & 2.44 & 2.43 & 99.1 & $\begin{array}{l}\text { \%RSD }=0 . \\
61\end{array}$ \\
\hline 1. & $100 \%$ & 2.48 & 2.47 & 101.5 & $\begin{array}{l}\text { Mean }=2.4 \\
6\end{array}$ \\
\hline 2. & $100 \%$ & 2.45 & 2.45 & 100 & $\begin{array}{l}\mathrm{SD}=0.015 \\
2\end{array}$ \\
\hline 3. & $100 \%$ & 2.47 & 2.47 & 100.8 & $\begin{array}{l}\text { \%RSD }=0 . \\
617\end{array}$ \\
\hline 1. & $150 \%$ & 2.51 & 2.50 & 101 & $\begin{array}{l}\text { Mean }=2.5 \\
1\end{array}$ \\
\hline 2. & $150 \%$ & 2.50 & 2.49 & 102 & $\mathrm{SD}=0.01$ \\
\hline \multirow[t]{2}{*}{3.} & $150 \%$ & 2.52 & 2.51 & 102 & $\begin{array}{l}\% \mathrm{RSD}=0 . \\
48\end{array}$ \\
\hline & & & & $\begin{array}{l}\text { Mean=10 } \\
0.3 \\
\mathrm{SD}=1.414 \\
\% \mathrm{RSD}=1 \\
40\end{array}$ & \\
\hline
\end{tabular}

For repeatability, six same standard preparations were made and the relative standard deviation for the replicate samples was calculated. The readings of system precision were given in the Table 2. Results meet the established acceptance criteria where the correlation coefficient is 0.999 . 
Indo Global Journal of Pharmaceutical Sciences, 2018; 8(2): 76-79

Table 2: Precision data of iron samples in biological samples

\begin{tabular}{|c|c|c|}
\hline S.No & $\begin{array}{c}\text { Concentration } \\
(\boldsymbol{\mu g} / \mathbf{m L})\end{array}$ & Absorbance $(\mathbf{n m})$ \\
\hline 1. & 28 & 0.164 \\
\hline 2. & 28 & 0.166 \\
\hline 3. & 28 & 0.162 \\
\hline 4. & 28 & 0.166 \\
\hline 5. & 28 & 0.168 \\
\hline 6. & 28 & 0.164 \\
\hline & & $\begin{array}{c}\text { Mean }=0.165 . \\
\text { SD }=0.00209 . \\
\% \mathrm{RSD}=1.26 .\end{array}$ \\
\hline
\end{tabular}

\section{CONCLUSION}

A simple, sensitive and highly selective direct colorimetric method for the determination of Iron in biological samples was developed. The method was applied successfully for the determination of biological samples (liver of female Wister rats). The method was very simple, economical, rapid method. It can be used in laboratory purpose for the quantitative estimation of iron.

\section{ACKNOWLEDGEMENT}

The authors duly acknowledge Nirmala College of Pharmacy, Mangalagiri, Guntur, Andhra Pradesh for providing necessary research facilities to carry out this research.

\section{REFERENCES}

1. J.E. Fergusson, The Heavy Elements: Chemistry, Environmental Impact and Health Effects, Pergamon Press, Oxford, 1990, pp. 85547.

2. WHO, UNICEF, and UNU, Iron Deficiency Anemia: Assessment, Prevention and Control, A Guide for Programme Managers, WHO, UNICEF, UNU, Genevai, Switzerland, 2001,

3. M. B. Zimmermann and R. F. Hurrell, "Nutritional iron deficiency," The Lancet, vol. 370, pp. 511-520, 2007.

4. R. D. Baker, F. R. Greer, and Committee on Nutrition American Academy of Pediatrics, "Diagnosis and prevention of iron deficiency and iron-deficiency anemia in infants and young children ( $0-3$ years of age)," Pediatrics, vol. 126, pp. 1040-1050, 2010.

5. F. Arnold, S. Parasuraman, P. Arokiasamy, and M. Kothari, "Nutrition in India" in National Family Health Survey (NFHS-3) India 2005-062009, http://www.rchiips.org.

6. Office of The Registrar General \& Census Commissioner, Census of India.

7. www.speclab.com

8. Skoog West, Fundamentals of Analytical Chemistry 2nd edition, chapter 29.

9. Vogel, A Textbook of Quantitative Inorganic Analysis, 3rd edition, p.no 294 .

10. Hematological and biochemical effects of sub-chronic artesunate exposure in rats.

11. A rapid spectrophotometric method for the determination of mercury in environmental, biological, soil and plant samples using diphenylthiocarbazone.

12. ICH guidelines.

13. NNR (Nordic Council of Ministers), (2004). Iron, In: Nordic Nutrition Recommendations 2004; Integrating nutrition and physical activity, 4th ed. Copenhagen

14. Sprouting Jar Strainer Lid by Handy Pantry. Hakone, Hiranandani Gardens, Powai, Mumbai, Maharashtra 400076. www.headrush.in/contact/

15. Indian Pharmacopeae 2007.

Indo Global Journal of Pharmaceutical Sciences( ISSN 22491023 ; UGC Journal No.: 44477; CODEN- IGJPAI; NLM ID: 101610675) indexed and abstracted in EMBASE(Elsevier), UGC Journal List, National Library of Medicine (NLM) Catalog, Elsevier( EMBASE), ResearchGate, Publons, CAS (ACS), Index Copernicus, Google Scholar and many more. For further details, visit http://iglobaljournal.com 